\title{
Reversible cardiotoxicity in a 54-year-old woman treated with trastuzumab
}

\author{
SANDRO JOSÉ MARTINS ${ }^{1}$, VITORINO MODESTO DOS SANTOS ${ }^{2}$, \\ LUDMILA THOMMEN TELES ${ }^{3}$, VIVIANE ALVES LEITE ${ }^{3}$
}

\begin{abstract}
We report a 54-year-old woman with an stage IIA (T2NOMO) RE and RP negative and HER2-positive ductal invasive breast cancer who developed a reversible cardiotoxicity associated with chemotherapy. After surgery, she received four cycles of doxorubicin and cyclophosfamide. Later, she used paclitaxel and trastuzumab. At the $7^{\text {th }}$ cycle of trastuzumab, she had symptoms of heart failure with left ventricle ejection fraction $=59 \%$. Trastuzumab dosage was reduced in 25\%, and heart function progressively improved. Two years after her discharge, the patient remains asymptomatic. Systolic function of the left ventricle was normal before the initial dosis of trastuzumab, but significantly worsened following the beginning of drug administration. Moreover, a clear improvement of heart function was observed soon after the daily dose of trastuzumab was reduced. Better knowledge of risk factors for cardiotoxicity related to chemotherapy, and longstanding surveillance with serial echocardiograms can avoid more severe cardiotoxicity by chemotherapy.
\end{abstract}

(Rev Med Chile 2012; 140: 763-766).

Key words: Breast neoplasms; Chemotherapy, adjuvant; drug toxicity; stroke volume; trastuzumab.

\section{Cardiotoxicidad reversible en una mujer con 54 años tratada con trastuzumab}

Se reporta un caso de cardiotoxicidad asociada con quimioterapia con trastuzumab, en una mujer con 54 años de edad que presentó un cáncer de mama ductal invasivo, con receptores de estrógeno y de progesterona negativos y HER2-positivo, en estadio IIA (T2NOMO). En el posoperatorio, recibió cuatro ciclos de doxorubicina y ciclofosfamida. Después recibió paclitaxel y trastuzumab. En el séptimo ciclo de trastuzumab, la paciente presentó sintomas de falla cardiaca, con fracción de eyección de ventrículo izquierdo $=59 \%$. La dosis de trastuzumab fue reducida en 25\%, y la función cardiaca se normalizó progresivamente. Más de 2 años después del alta hospitalaria, permanece sin sintomas. En esta paciente la función sistólica de ventrículo izquierdo estaba normal previo al uso de trastuzumab y hubo un significativo deterioro desde el início de este medicamento. Se observó una mejoría importante en la función cardiaca cuando se redujo la dosis diaria de trastuzumab. Un mejor conocimiento acerca de los factores de riesgo para cardiotoxicidad relacionados con quimioterapia y el seguimiento prolongado con ecocardiogramas pueden evitar la cardiotoxicidad más severa debida a quimioterapia.
'Oncology Division from Armed Forces Hospital (HFA), Brasília-DF, Brazil. ${ }^{2}$ Catholic University (UCB) and Internal Medicine Department from HFA. ${ }^{3}$ Internal Medicine Department from HFA.

There was no grant support for this study. Disclosure of potential conflicts of interest: The authors had full freedom of manuscript preparation and there were no potential conflicts of interest.

Received August 8, 2011 Accepted December 2, 2011.

Corresponding author: Prof. Dr. Vitorino Modesto dos Santos, Armed Forces Hospital.

Estrada do Contorno do Bosque s/n, Cruzeiro Novo, 70658-900, Brasília-DF, Brazil.

Phone: \#55-61 39662103 Fax: \#55-61 32331599 E-mail: vitorinomodesto@ gmail.com 
$\mathrm{B}$ reast cancer is the main cause of cancer among Latin American women and constitutes the second cause of death by cancer in Chile. The treatment of this cancer has satisfactorily evolved in the last decades, with clear improvement in morbidity and mortality rates ${ }^{1-3}$. New diagnosis resources and more effective therapy schedules have contributed to increase the survival of patients with more aggressive breast cancer that over-expresses or amplifies the HER2 gene ${ }^{1-4}$. Nevertheless, adverse effects of chemotherapy (CT) agents, including cardiotoxicity, have been more often observed and this can negatively affect both quality of life and outcome of patients from this group ${ }^{1,3,5,6}$. Trastuzumab (a monoclonal antibody targeting the HER2 gene) and paclitaxel (an antimicrotubule agent) have been employed with success to treat HER2 positive breast cancer $^{1-3,5}$. The incidence of cardiac adverse events associated with isolated use of trastuzumab ranges from 2 to $4 \%^{1,3,5,7}$; and may increase up to $16 \%$ with previous use of anthracycline and/or cyclophosphamide ${ }^{1,3-7}$. Trastuzumab has been administered in combination with placlitaxel to treat women who have not previously received CT for metastatic breast cancer ${ }^{8}$. Asymptomatic arrhythmias occur in association with the use of paclitaxel, and more severe cardiac adverse effects are related to CT schedules containing anthracyclines ${ }^{1,3,6,9}$. The concomitant use of trastuzumab and paclitaxel has been also associated with increased risk of cardiotoxicity ${ }^{8}$.

\section{Case report}

A 54-year-old-woman, diabetic and hypertensive, presented with a nodule in the left breast and the mammography study showed a dense image (Figure 1A and B). Tissue samples from fine needle aspiration revealed histological features of invasive ductal carcinoma and ductal carcinoma in situ. The immune histochemical study showed that tumor cells were negative for estrogen or progesterone receptors, and positive for HER2 receptor (Figure 1C). Additionally, neoplastic cells were positive for Ki-67 (50\%), c-erB-2 (3+), and p53 clone D01 (50\%). The patient was operated on with a quadrant excision and sentinel lymph node dissection. The pathologic stage of her tumor was IIA (T2N0M0). After surgery, she received adjuvant CT with four cycles of doxorubicin $\left(60 \mathrm{mg} / \mathrm{m}^{2}\right)$ and cyclophosfamide $\left(600 \mathrm{mg} / \mathrm{m}^{2}\right)$, followed by four cycles of trastuzumab $(8 \mathrm{mg} / \mathrm{kg}$ and $6 \mathrm{mg} / \mathrm{kg}$ every three weeks) and placlitaxel $\left(175 \mathrm{mg} / \mathrm{m}^{2}\right.$ every three weeks). We planned to deliver 13 additional cycles of trastuzumab monotherapy $(6 \mathrm{mg} / \mathrm{kg}$ every three weeks). Before treatment, the echocardiogram showed normal systolic function of the left ventricle (LV), with ejection fraction (EF) of $76 \%$. At the $7^{\text {th }}$ cycle of trastuzumab, the patient presented with dyspnea after exercise, fatigue, weakness and tachycardia, and her LVEF was 59\%. She started angiotensin-converting enzyme (ACE) inhibitor (captopril $12.5 \mathrm{mg}$ tid) and $\mathrm{CT}$ dose was reduced in $25 \%$. The following CT cycles were uneventful, and on physical examination 1 year later she was asymptomatic and her LVEF returned to the normal range $(75 \%)$. The patient is actually in good clinical condition, and under outpatient close surveillance.

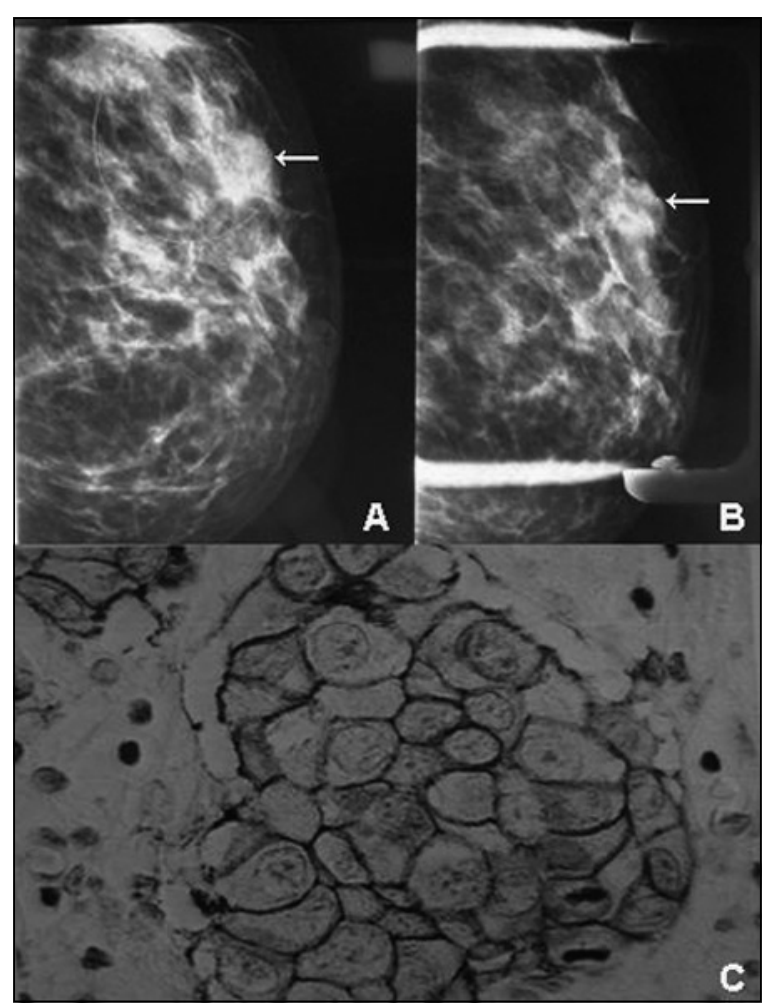

Figure 1. A and B. Mammographic image of the nodule in the left breast (arrows) in June, 2008. 1C. Immunohistochemistry features of the neoplastic cells positive $(3+)$ for c-erbB-2. 
Table 1. Comparative echocardiographic data of a 54-year-old female who had reversible cardiotoxicity due to chemotherapy with trastuzumab for HER2-positive breast cancer

\begin{tabular}{|lcccccc|}
\hline Parameter/day & $\mathbf{3 / 3 0 / 2 0 0 9}$ & $\mathbf{9 / 1 6 / 2 0 0 9 *}$ & $\mathbf{1 / 7 / 2 0 1 0}$ & $\mathbf{1 / 2 6 / 2 0 1 0}$ & $\mathbf{2 / 2 4 / 2 0 1 0 \#}$ & $\mathbf{6 / 3 / 2 0 1 0 \#}$ \\
Aorta SD (mm) & 36 & 36 & 39 & 38 & 33 & 35 \\
LASD (mm) & 38 & 31 & 41 & 38 & 38 & 32 \\
RVDD (mm) & 21 & 20 & 27 & 26 & 20 & 20 \\
LVDD (mm) & 47 & 46 & 48 & 47 & 44 & 44 \\
LVSD (mm) & 26 & 29 & 33 & - & 31 & 25 \\
Sept (mm) & 0.9 & 0.8 & 1.0 & 0.8 & 0.9 & 1.0 \\
LVPW (mm) & 0.9 & 0.8 & 0.9 & 0.8 & 0.8 & 1.0 \\
LVEF (\%) & 76 & 67 & 59 & 55 & 57 & 75 \\
LV mass (mg) & 179 & 148 & 199 & 103 & 148 & 185 \\
Sept/LVPW & 1.00 & 1.00 & 1.11 & 1.00 & 1.13 & 1.00 \\
SVol (ml) & 78 & 65 & 63 & - & 50 & 65 \\
End SVol (ml) & 25 & 32 & 44 & - & 38 & 22 \\
\hline
\end{tabular}

SD: systolic diameter; LA: left atrium; RV: right ventricle; DD: diastolic diameter; LV: left ventricle; Sept: ventricular septum; PW: posterior wall; EF: ejection fraction; SVol: sistolic volume. *: Initial adjuvant chemotherapy; \#: reduced doses of trastuzumab.

\section{Discussion}

The addition of trastuzumab to neoadjuvant and palliative CT can promote conspicuous improvement in the survival time of patients with breast cancer ${ }^{10}$. Nevertheless, adverse effects including cardiotoxicity, are growing in frequency and deserve a close accurate follow-up ${ }^{11}$. A major concern is about patients with cardiopathy, old age, and previous utilization of cardiotoxic drugs or thoracic irradiation, because they are more prone to develop severe cardiotoxicity $y^{1,3,7,12}$. Other potential risk factors include diabetes mellitus, high or low body mass index, hyperlipidemia, hypertension, thyroid dysfunction, and tobacco smoking ${ }^{8,13,14}$. Cardiotoxicity may be acute (soon after the administration of CT agents) or late (up to 12 years after the completion of CT course $)^{12}$. Systematic evaluation of heart function must precede treatment and the careful cardiologic follow-up of patients receiving CT agents must be longstanding ${ }^{11,13,14}$. Echocardiogram is the non-invasive test of choice for assessment of the LVEF, contributing to the early detection and prompt management of systolic and/or diastolic dysfunction secondary to treatment ${ }^{1,12-14}$.

Trastuzumab is a humanized monoclonal antibody that binds to the juxtamembrane extra- cellular portion of the transmembrane orphan receptor HER2 ${ }^{1,15}$. The nature of cadiotoxicity associated with the use of trastuzumab is not entirely understood. The mechanisms of action include enhancing of complement-mediated tumor lysis and chemotherapy-induced cytotoxicity, and down-regulation of receptor expression ${ }^{8}$. This drug may cause non-symptomatic and reversible decrease of LVEF in a great number of patients, and the main symptoms include palpitation, tachycardia, dyspnea, thoracic pain, and evolution with congestive heart failure $e^{14,15}$. Therapeutic schedules frequently include discontinuing or lower doses of trastuzumab, in addition to the control of associated risk factors and the use of ACE inhibitors and beta-blockers ${ }^{1,8,15}$.

Paclitaxel is a drug of the taxane group, which may cause acute asymptomatic sinus bradycardia in up to $30 \%$ of treated patients, and its cardiovascular side effects include heart block, premature ventricular complexes, ventricular tachycardia, and thrombosis ${ }^{1,3}$. Paclitaxel monotherapy and its association with trastuzumab may cause cardiac dysfunction ${ }^{1,3,8}$, and the taxane can enhance the cardiotoxicity of antracyclines by interfering with the metabolism and excretion of these drugs ${ }^{1,3}$. Cardiac adverse events must be anticipated in combination $\mathrm{CT} ;{ }^{3}$ lower dosage and increased interval 
between the administration of drugs reduce the occurrence of cardiotoxicity ${ }^{1,3}$. In our patient, major predisposing factors for cardiac adverse events of trastuzumab were present, as diabetes mellitus, hypertension and previous use of antracycline and cyclophosfamide ${ }^{14}$. Despite of the combination with taxane, the reduction of trastuzumab dosage led to normalization of LVEF, and the patient is under regular ambulatory surveillance without heart disturbances. Better knowledge about risk factors for cardiotoxicity related to CT contributes to reduce the cardiovascular adverse effects. Early and long term control by serial echocardiograms is needed to characterize this condition and play a role in favorable outcomes by avoiding the progression of mild ventricular dysfunction to a more severe and irreversible cardiac failure ${ }^{1,3,8,12}$. Tissue velocity imaging is another non-invasive method to evaluate the left ventricle function in patients under CT with trastuzumab. Peak systolic myocardial velocity and peak global longitudinal and radial strain can disclose disturbances in systolic function, before the characterization of changes in the LVEF demonstrated by echocardiography ${ }^{16}$.

Although with the limitation of a single case study, the present data can contribute to highlight the potential reversibility of trastuzumab cardiotoxicity, even after the utilization of doxorubicin and cyclophosfamide, as well as with the concomitant administration of paclitaxel for breast cancer. Case reports may increase the awareness about cardiotoxicity induced by cancer chemotherapy.

\section{References}

1. Bird BRJH, Swain SM. Cardiac toxicity in breast cancer survivors: review of potential cardiac problems. Clin Cancer Res 2008; 14: 14-24.

2. Chang HR. Trastuzumab-based neoadjuvant therapy in patients with HER2-positive breast cancer. Cancer 2010; 116: 2856-67.

3. Yeh ETH, Tong AT, Lenihan DJ, Yusuf SW, Swafford J, Champion C, et al. Cardiovascular complications of cancer therapy: diagnosis, pathogenesis, and management. Circulation 2004; 109: 3122-31.

4. Untch M, Rezai M, Loibl S, Fasching PA, Houber J, Tesch $\mathrm{H}$, et al. Neoadjuvant treatment with trastuzumab in HER2-positive breast cancer: results from the GeparQuattro Study. J Clin Oncol 2010; 28: 2024-31.
5. Jones AL, Barlow M, Barrett-Lee PJ, Canney PA, Gilmour IM, Robb SD, et al. Management of cardiac health in trastuzumab-treated patients with breast cancer: updated United Kingdom National Cancer Research Institute recommendations for monitoring. Br J Cancer 2009; 100: 684-92.

6. Senkus E, Jassem J. Cardiovascular effects of systemic cancer treatment. Cancer Treat Rev 2011; 37: 300-11.

7. Safra T. Chemotherapeutics and cardiac toxicity: treatment considerations and management strategies. Commun Oncol 2007; 4: 540-8.

8. Keefe DL. Trastuzumab-associated cardiotoxicity. Cancer 2002; 95: 1592-600.

9. Gianni L, Dombernowsky P, Sledge G, Martinn M, Amadori D, Arbuck G, et al. Cardiac function following combination therapy with paclitaxel and doxorubicin: an analysis of 657 women with advanced breast cancer. Ann Oncol 2001; 12: 1067-73.

10. Guarnieri V, Barbieri E, Dieci MV, Piacentini F, Conte P. Anti-HER2 neoadjuvant and adjuvant therapies in HER2 positive breast cancer. Cancer Treat Rev 2010; 36: S62-6.

11. Tanz R, Mahfoud T, Bazine A, Khmamouch R, Bensouda $\mathrm{Y}$, Ismaili $\mathrm{N}$, et al. [Cardiac safety of trastuzumab in adjuvant: A review across 53 observations.] J Gynecol Obstet Biol Reprod (Paris) 2011; 40: 144-8.

12. Galderisi M, Marra F, Esposito R, Lomoriello VS, Pardo M, Divitiis O. Cancer therapy and cardiotoxicity: The need of serial doppler echocardiography. Cardiovasc Ultrasound 2007; 5 :4. doi: 10.1186/1476-7120-5-4.

13. Saad A, Abraham J. Trastuzumab and cardiac toxicity: monitoring in the adjuvant setting. Commun Oncol 2007; 4: 739-44.

14. Suter TM, Procter M, Van Veldhuisen DJ, Muscholl M, Bergh J, Carlomagno C, et al. Trastuzumab-associated cardiac adverse effects in the herceptin adjuvant trial. J Clin Oncol 2007; 25: 3859-65.

15. Mackey JR, Clemons M, Côté MA, Delgado D, Dent S, Paterson, et al. Cardiac management during adjuvant trastuzumab therapy: recommendations of the Canadian Trastuzumab Working Group. Curr Oncol 2008; 15: 24-35.

16. Fallah-Rad N, Walker JR, Wassef A, Lytwyn M, Bohonis $\mathrm{S}$, Fang T, et al. The utility of cardiac biomarkers, tissue velocity and strain imaging, and cardiac magnetic resonance imaging in predicting early left ventricular dysfunction in patients with human epidermal growth factor receptor II-positive breast cancer treated with adjuvant trastuzumab therapy. J Am Coll Cardiol 2011; 57: 2263-70. 